\title{
Tuberculosis in a Portuguese Cohort
}

\author{
António Guerra Maio, Daniel Coutinho, Sofia Nunes, Jorge Velez, Filomena Freitas, Célia Oliveira
}

Infectious Diseases Department, Centro Hospitalar do Baixo Vouga - Aveiro, Portugal

\begin{abstract}
Background: Tuberculosis (TB) is a multisystemic disease and a leading cause of infectious disease-related mortality worldwide. Objectives: This study aims to characterize patients with TB in a portuguese cohort.

Methods: Retrospective analysis of files pertaining inpatients with TB admitted between 1/2005 - 12/2014. Data were analysed using $\chi 2$ or Fisher exact test $(p<0.005=$ statistically significant) and odds ratio was calculated.

Results: 222 cases were found: 128 patients had pulmonary involvement (PTB) and 100 extrapulmonary disease (ETB) (6 had overlapping disease), with men being mostly affected. The most common locations of ETB were lymphatic (27.0\%), meningeal and osteoarticular (both 19.0\%).

The majority exhibited risk factors $(64.0 \%, p<0.005)$. PTB was associated with smoking $(p=0.000,0 R=5.05)$ and contact with TB-infected person $(p=0.002,0 R=7.53)$. Human immunodeficiency virus (HIV) infection $(p=0.000,0 R=5.16)$ and age $>65(p=0.005,0 R=3.34)$ were associated with ETB. 48 patients were HIV-infected, with median CD4 count of 74.5 cells/ $\mu \mathrm{L}$ (13-136), most cases occurring in the setting of new HIV diagnosis. HIV infection was statistically associated with disseminated $(\mathrm{OR}=12.64)$, pleural $(\mathrm{OR}=8.50)$, meningeal $(\mathrm{OR}=2.96)$ and lymphatic $\mathrm{TB}(\mathrm{OR}=2.38)$. HIV negativity was associated with pulmonary $(\mathrm{OR}=4.08)$ and osteoarticular disease $(\mathrm{OR}=5.42)$.

PTB was confirmed mainly by culture or PCR test plus smear (81.3\%). ETB diagnosis was more complex.

Clinical outcome was favourable (PTB 98.4\%; ETB 94.0\%). Eight patients died.

Conclusions: TB remains an important healthcare issue in Portugal. Contact with TB-infected person and smoking (PTB) and HIV infection and age $>65$ (ETB), were significant risk factors. HIV infection was associated with disseminated, pleural, meningeal and lymphatic disease.

Keywords: Tuberculosis, Extrapulmonary, Pulmonary, HIV, Risk factors.
\end{abstract}

\section{Introduction}

Tuberculosis (TB) is one of the most common infections in the world, being an important cause of morbidity and mortality associated with infectious diseases. ${ }^{1}$

According to World Health Organization (WHO), in 2014, 9.6 million people fell ill with TB and, among these, 1.2 million were also infected with human immunodeficiency virus (HIV). It is known that TB ranks, along with HIV, as one of the leading causes of death worldwide: 1.5 million died from TB in 2014, 0.4 million being co-infected with HIV. Adult women, aged between 20-59 years, seem to be particularly at risk, being TB one of the top five killers in this group. TB death rate decreased $47.0 \%$ since 1990 but, even so, the disease is becoming more common in many parts of the world and drug-resistance is increasing. Co-infection with HIV seems to be an important factor in the emergence and spread of such cases. ${ }^{2}$

The incidence and prevalence of TB is decreasing in Portugal. The incidence rate decreased from 39.3 to 20.0/100,000 per year between 2005 and 2014. The prevalence rate decreased from 37.2 to $29.0 / 100,000$ population per year on the same time period. ${ }^{3-5}$ There is an asymmetry in the incidence of tuberculosis in Portugal. Coastal districts have a greater number of cases than those inland. Oporto, Lisbon, Setúbal and the Algarve are the regions with higher incidence (between 20.0 and 50.0/100,000). The region of Aveiro, although located in a coastal area, had an incidence of $15.6 / 100,000$ in 2014 . $^{6-7}$

TB is caused by a bacillus from the Mycobacterium tuberculosis complex that includes M. tuberculosis (accounting for
97-99\% of cases), M. africanum, M. microti, and M. bovis. After infection, four possible outcomes can occur: immediate clearance of the microorganism, primary disease, latent infection and later reactivation of the disease. In most cases, after contact with M. tuberculosis, $90 \%$ of those with intact immune systems will control replication of the bacilli, entering a latent phase. Approximately 5 to $10 \%$ of patients without underlying medical problems will have reactivation of the disease during their lifetime. ${ }^{1,8-9}$ This risk is largely increased if there is co-infection with HIV. ${ }^{10}$

The disease is a chronic necrotizing mycobacterial infection characterized by the development of granulomatous lesions. It can affect almost every organ in the body with the lungs being most commonly involved. Other organs and/or locations, like the lymph nodes, pleura, abdomen, joints/bone or the meninges, can be affected. ${ }^{1,8,11-12}$ The proportion of patients with extrapulmonary (ETB) or pulmonary TB (PTB) varies along different world regions. ${ }^{13-18}$ ETB is more frequent in people with a compromised immune system, as is the case in HIV-infected patients. ${ }^{11,12}$

Some patients have characteristics that put them at risk of acquiring TB. ${ }^{1,8}$ Some factors recognized as risk factors for TB are smoking ${ }^{19-20}$, presence of any immunosuppression status (use of immunosuppressive drugs, cancer or HIV infection $)^{10,21-27}$, younger or older age ${ }^{28,29}$, migrant status ${ }^{30-32}$, inmate status ${ }^{31,33}$, homelessness or institutionalization ${ }^{31,34,35}$, close contact with TB-infected patients ${ }^{36,37}$, drug use ${ }^{38}$, alcoholism $^{39}$, malnutrition ${ }^{40}$, diabetes ${ }^{41-42}$ and other chronic comorbidities $^{43-45}$. Obesity ${ }^{46}$ and female gender ${ }^{47}$ seem to reduce the risk of acquiring TB. 
Early diagnosis is essential to minimize morbidity and mortality from this disease. This can be difficult due to non-specific and/or insidious complaints, being essential a high level of suspicion. The use of acid-fast bacilli smears aids towards an early presumptive diagnosis, but the disease is only confirmed with a positive culture for $M$. tuberculosis, which can take weeks to obtain. Other techniques are used to provide early diagnosis, like nucleic acid amplification. Most often, diagnosis is obtained from a combination of different diagnostic methods. 1,8,11,48

Treatment of TB should be initiated early to achieve best outcomes, avoiding further transmission and complications from more advanced disease. There are various treatment regimens, but the most often used are based on isoniazid, rifampicin, pyrazinamide and ethambutol - the use of at least four drugs has the objective to avoid drug resistance. These drugs are used for at least two months (initial phase) and, after negative cultures are obtained, pyrazinamide and ethambutol can be suspended and the other drugs maintained for a period that varies (maintenance phase) according to the form of disease being treated. ${ }^{49-50}$

This study tries to characterize patients with TB in a portuguese cohort, comparing patients with PTB and ETB, focusing in aspects like the incidence of tuberculosis, risk factors, clinical manifestations, diagnosis, treatment and also particular aspects of patients with concomitant HIV infection. Objectively, we aimed at figuring out clinical characteristics that can help to better recognize and manage this disease.

\section{Material/Methods}

This study consisted on a retrospective record file analysis of patients, aged over 15 years old, who were hospitalized in the Infectious Diseases Ward in Centro Hospitalar do Baixo Vouga - Aveiro, Portugal, between 1/1/2004 and 31/12/2014, with diagnosis of TB. This hospital covers an area with a population around 360,000 people. ${ }^{5}$ Some patients that do not warrant hospitalization are treated at Directly Observed Treatment (DOT) centres. Those that do require hospital admission are usually admitted to our ward.

The diagnosis of PTB and ETB was made in harmony with WHO criteria. ${ }^{48}$ PTB was considered if the infection affected the lung parenchyma and ETB if there was involvement of any other organ. If a patient presented with radiographic findings characteristic of disseminated disease, he was deemed as having ETB. Isolated pleural involvement was also included in the ETB group. Patients with lung infection and other organ involvement were accounted for in both groups. Investigation of simultaneous presence of PTB in ETB patients was made by routine in all but not extensively.

Diagnosis of TB was defined as "confirmed" if there was identification of $M$. tuberculosis through Ziehl-Neelsen acid-fast stain plus a positive PCR or by culture in Lowenstein-Jensen media. It was deemed "probable" if there was a positive PCR, a positive acid-fast stain or a compatible histology. Lastly, the diagnosis was considered "possible" when the patient received empirical TB treatment and had favourable clinical, analytical and imaging response. Some analytical exams like adenosine deaminase (ADA) levels were accounted for in those situations where diagnosis was more complex.

Patients were treated with antituberculosis drugs as usually recommend in guidelines. In some cases (like meningeal, pericardic or pleural forms of TB) corticosteroids were used as adjunctive therapy. ${ }^{48-50}$

HIV infection was determined by serum enzyme-like immunosorbent assay (ELISA) with INNO-LIA confirmation. A quantifiable HIV viral load also confirmed the diagnosis.

Patients were excluded if they were transferred to other hospitals during hospitalization or if data were not available in the record files.

Data were evaluated using IBM SPSS statistics software version 23. Differences in categorical variables were evaluated using Pearson $\chi^{2}$ test or Fisher's exact test. The strengths of associations were presented by odds ratio (OR) with $95.0 \%$ confidence intervals. For all tests a $p$-value $<0.05$ was considered statistically significant.

\section{Results}

A total of 225 patients were diagnosed with TB during the study period. Three patients were excluded due to being transferred to other hospitals and/or not having clinical information, thus a total of 222 patients was analysed. Of these, 128 patients (57.7\%) had pulmonary involvement and 100 (45.0\%) had an extrapulmonary form of TB (six patients had simultaneous pulmonary and extrapulmonary involvement). Baseline characteristics are described in table 1.

Extrapulmonary forms of tuberculosis are described in table 2. Twelve patients had infection in more than one location. The most common locations were lymphatic $(27.0 \%)$, meningeal (19.0\%), osteoarticular (19.0\%) and disseminated (15.0\%).

The majority had at least one risk factor for infection with $M$. tuberculosis $(n=142,64.0 \%)$. The main risk factors in the study population are described in table 3.

The most frequent risk factors for patients with PTB were being a smoker $(n=37)$, alcoholism $(n=21)$, contact with a TB-infected person $(n=18)$, poor socioeconomic condition ( $n=16)$ and HIV infection $(n=15)$. In the ETB group the most common were HIV infection $(n=36)$, age over 65 years $(n=19)$ and alcoholism / poor socioeconomic condition (both, $n=11$ ).

There was an increased risk of acquisition of PTB if there was contact with TB-infected persons (OR 7.53), smoking (OR 5.05), use of immunosuppressive therapy or institutionalization (OR 4.57). Being infected with HIV (OR 5.16) and being older than 65 years (OR 3.34) increased the risk for acquisition of ETB.

Time from onset of symptoms to diagnosis was obtained in $60.8 \%$ of cases ( $n=135 ; 75$ in PTB and 60 in ETB). Patients with PTB had duration of symptoms shorter than 90 days 
Table 1. Baseline characteristics of the study population

\begin{tabular}{|c|c|c|c|c|c|c|c|c|}
\hline & \multicolumn{4}{|c|}{ Pulmonary Tuberculosis } & \multicolumn{4}{|c|}{ Extrapulmonary Tuberculosis } \\
\hline & Total & Men & Women & $p$-value & Total & Men & Women & $p$-value \\
\hline $\begin{array}{l}\text { Number of } \\
\text { cases }\end{array}$ & $\begin{array}{c}128 \\
(57.7 \%)\end{array}$ & $\begin{array}{c}98 \\
(76.6 \%)\end{array}$ & $\begin{array}{c}30 \\
(23.4 \%)\end{array}$ & 0.001 & $\begin{array}{c}100 \\
(45.0 \%)\end{array}$ & $\begin{array}{c}56 \\
(56.0 \%)\end{array}$ & $\begin{array}{c}44 \\
(44.0 \%)\end{array}$ & 0.001 \\
\hline $\begin{array}{l}\text { Median age } \\
\text { (years) }\end{array}$ & $\begin{array}{c}40 \\
\text { IQR [29.5-50.5] }\end{array}$ & $\begin{array}{c}42 \\
\text { IQR [32.0-50.8] }\end{array}$ & $\begin{array}{c}35,5 \\
\text { IQR [26.3- 45.8] }\end{array}$ & 0.000 & $\begin{array}{c}44,5 \\
\text { IQR [35.0-57.0] }\end{array}$ & $\begin{array}{c}48 \\
\text { IQR [35.8-56.6] }\end{array}$ & $\begin{array}{c}49 \\
\text { IQR [30.0-64.5] }\end{array}$ & 0.058 \\
\hline $\begin{array}{l}\text { Country of } \\
\text { origin }\end{array}$ & \multicolumn{3}{|c|}{$\begin{array}{l}\text { - Portugal }(n=121) \\
\text { - Angola }(n=2) \\
\text { - } \text { Guinea Bissau (n=2) } \\
\text { - } \text { Brazil }(n=1) \\
\text { - } \text { Romania }(n=1) \\
\text { - } \\
\text { East Timor }(n=1)\end{array}$} & & \multicolumn{3}{|c|}{$\begin{array}{l}\text { - Portugal ( }(n=94) \\
\text { - São Tomé and Príncipe }(n=4) \\
\text { - Angola }(n=2) \\
\text { - Guinea Bissau }(n=2) \\
\text { - } \text { Brazil }(n=1) \\
\text { - } \text { Romania }(n=1) \\
\text { - } \quad \text { East Timor }(n=1) \\
\end{array}$} & \\
\hline $\begin{array}{l}\text { Length of stay } \\
\text { (days) }\end{array}$ & \multicolumn{3}{|c|}{17 (IQR 11.0-24.0) } & 0.064 & \multicolumn{3}{|c|}{$18($ IQR 8,8-27,8) } & 0.076 \\
\hline \multirow{2}{*}{$\begin{array}{l}\text { Year of } \\
\text { hospitalization } \\
\text { (n) }\end{array}$} & $2005-2009$ & \multicolumn{2}{|c|}{ 2010-2014 } & \multirow{2}{*}{0.004} & $2005-2009$ & \multicolumn{2}{|c|}{$2010-2014$} & \\
\hline & $70(54.7 \%)$ & \multicolumn{2}{|c|}{58 (45.3\%) } & & $60(60.0 \%)$ & \multicolumn{2}{|c|}{$40(40.0 \%)$} & 0.000 \\
\hline
\end{tabular}

Table 2. Extrapulmonary TB locations

\begin{tabular}{|c|c|c|c|c|}
\hline & \multicolumn{4}{|c|}{ Extrapulmonary Tuberculosis } \\
\hline & Total (n) & $\begin{array}{l}\text { Men } \\
\text { (n) }\end{array}$ & $\begin{array}{l}\text { Women } \\
\text { (n) }\end{array}$ & Median Age (years) \\
\hline Lymphatic & 27 & 16 & 11 & $\begin{array}{c}33 \\
\text { IQR [29.5-54.0] }\end{array}$ \\
\hline Meningeal & 19 & 11 & 8 & $\begin{array}{c}43 \\
\text { IQR [31.5-69.0] }\end{array}$ \\
\hline Osteoarticular & $\begin{array}{c}19 \\
\text { Dorsal: } n=7 \\
\text { Lumbar: } n=12 \\
\text { Hip: } n=1\end{array}$ & 9 & 10 & $\begin{array}{c}54 \\
\text { IQR [51.5-66.0] }\end{array}$ \\
\hline Disseminated & 15 & 10 & 5 & $\begin{array}{c}46 \\
\text { IQR [41.0-67.5] }\end{array}$ \\
\hline Gastrointestinal & $\begin{array}{c}13 \\
\text { Hepatic: } n=1 \\
\text { Intestinal: } n=6 \\
\text { Peritoneal: } n=7\end{array}$ & 6 & 7 & $\begin{array}{c}30 \\
\text { IQR }[24.0-45.0]\end{array}$ \\
\hline Pleural & 12 & 10 & 2 & $\begin{array}{c}32 \\
\text { IQR [30.3-43.5] }\end{array}$ \\
\hline Genitourinary & 3 & 1 & 2 & $\begin{array}{c}24 \\
\text { IQR }[24.0-40.0]\end{array}$ \\
\hline Pericardic & 3 & 2 & 1 & $\begin{array}{c}54 \\
\text { IQR [54.0-65.0] }\end{array}$ \\
\hline Cutaneous & 1 & 0 & 1 & 63 \\
\hline
\end{tabular}

[median 60 days - IQR (Interquartile Range) [22.5-97.5]; (0$30 ; n=35),(30-90 ; n=24),(\geq 90 ; n=16) ; p=0.017$. On the other hand, symptoms in ETB group varied between short and longer durations [median 30 days - IQR [1.0-94.0]; (0$30 ; n=35),(30-90 ; n=8),(\geq 90 ; n=21) ; p=0.029$ ].

In table 4 are described the main symptoms/signs in the two groups. Most frequent in the PTB group were cough (mainly productive), fever, weight loss, asthenia, anorexia and night sweats. On the other group fever, asthenia, anorexia and night sweats were also frequent. Some symptoms were, expectedly, more frequent in some forms of ETB like lymphadenopathies in lymphatic forms (27 of 30), altered mental status in meningeal forms (9 of 15) and back pain in osteoarticular forms (16 of 17).

The diagnosis of PTB was confirmed in the majority of cases $(n=104,81.3 \%)$. In 14 cases (10.9\%) it was defined as probable and in 10 cases $(7.8 \%)$ as possible. On the other hand, ETB was confirmed only in $14 \%$ of situations $(n=14)$, being defined as probable in $41 \%(n=41)$ and as possible in $45 \%(n=45)$. ETB patients with possible diagnosis were divided as follows: meningeal and osteoarticular (both, $n=17$ ), pleural $(n=5)$, pericardic and gastrointestinal (both, $n=3$ ).

In table 5 are described the main methods used for the diagnosis of tuberculosis in both groups.

A conventional chest $x$-ray was performed in every patient. Abnormalities were present in 119 exams in PTB group (93.0\%; p-value: 0.000) and in 54 in the ETB group (54.0\%; $p$-value: 0.000 . On the first group the main abnormalities were the presence of apical infiltrate $(\mathrm{n}=99,83.2 \%$; $p$-value: 0.000 ), cavitation ( $\mathrm{n}=79,66.4 \%$; $p$-value: 0.000 ), non-apical infiltrate $(n=19,16.0 \% ; p$-value: 0.000 and pleural effusion ( $\mathrm{n}=5,5.0 \% ; p$-value: 0.000 ). In the ETB group the abnormalities found were micronodular pattern $(n=15$, 27.8\%; $p$-value: 0.000 , pleural effusion $(n=13,24.1 \%$; $p$-value: 0.000 , apical and non-apical infiltrates (each with $\mathrm{n}=6,11.1 \% ; p$-value: 0.000 , cavitation $(\mathrm{n}=3 ; 5.6 \% ; p$-value: 0.000 and single nodule $(n=2 ; 3.7 \% ; p$-value: 0.000 .

Other tests were ordered mainly when there was suspicion of ETB forms, and comprised ultrasound, tomography and/or magnetic resonance imaging.

ADA was measured in patients where the diagnosis was more difficult and were classified as possible diagnosis of TB. Median ADA levels were 25,2 IU/L [18,4-42,5] in meningeal, 32,5 IU/L [22,5-42,7] in osteoarticular, 102,1 IU/L 
Table 3. Risk factors present at diagnosis. NA: non-applicable. OR: Odds ratio. TB: Tuberculosis

\begin{tabular}{|l|c|c|c|c|c|c|}
\hline & \multicolumn{3}{|c|}{ Pulmonary Tuberculosis $(\mathrm{n}=128)$} & \multicolumn{2}{c|}{ Extrapulmonary Tuberculosis $(\mathrm{n}=100)$} \\
\hline & Total & $p$-value & OR & Total & $p$-value & OR \\
\hline Presence of risk factors at diagnosis & $93(72.7 \%)$ & $N A$ & $N A$ & $55(55.0 \%)$ & NA & NA \\
\hline Alcoholism & $21(22.6 \%)$ & 0.141 & 1.85 & $11(20.0 \%)$ & 0.321 & 0.67 \\
\hline Contact with TB-infected person & $18(19.4 \%)$ & 0.002 & 7.53 & $3(5.5 \%)$ & 0.005 & 0.19 \\
\hline Diabetes & $6(6.5 \%)$ & 0.575 & 1.11 & $5(9.1 \%)$ & 0.757 & 1.23 \\
\hline Drug use & $10(10.8 \%)$ & 0.467 & 0.71 & $10(18.2 \%)$ & 0.641 & 1.24 \\
\hline HIV infection & $15(16.1 \%)$ & 0.000 & 0.25 & $36(65.5 \%)$ & 0.000 & 5.16 \\
\hline Migrant status & $8(8.6 \%)$ & 0.770 & 1.19 & $6(10.9 \%)$ & 0.934 & 1.05 \\
\hline Immunosuppressive therapy & $6(6.5 \%)$ & 0.243 & 4.57 & $1(18.2 \%)$ & 0.132 & 0.20 \\
\hline Institutionalization & $6(6.5 \%)$ & 0.243 & 4.57 & $2(3.6 \%)$ & 0.462 & 0.48 \\
\hline Neoplasia & $6(6.5 \%)$ & 0.040 & 1.77 & $0(0.0 \%)$ & $N A$ & $N A$ \\
\hline Age over 65 years & $8(8.6 \%)$ & 0.002 & 0.26 & $19(34.6 \%)$ & 0.005 & 3.34 \\
\hline Previous TB infection & $11(11.8 \%)$ & 0.983 & 1.01 & $8(14.6 \%)$ & 0.788 & 0.88 \\
\hline Poor socioeconomic condition & $16(17.2 \%)$ & 0.344 & 1.54 & $11(20.0 \%)$ & 0.934 & 1.04 \\
\hline Renal impairment & $2(2.2 \%)$ & 0.510 & $N A$ & $0(0.0 \%)$ & NA & NA \\
\hline Smoking & $37(39.8 \%)$ & 0.000 & 5.05 & $7(12.7 \%)$ & 0.000 & 0.17 \\
\hline
\end{tabular}

Note: p-value was calculated with Pearson $\chi 2$ test or Fisher's exact test. OR measured the odds of the presence of a risk factor in patients with pulmonary tuberculosis or extrapulmonary tuberculosis compared with the odds of not having that risk factor in the same group.

Table 4. Main signs and symptoms in patients with PTB and ETB

\begin{tabular}{|c|c|c|c|c|}
\hline & \multicolumn{2}{|c|}{ Pulmonary Tuberculosis $(n=128)$} & \multicolumn{2}{|c|}{ Extrapulmonary Tuberculosis $(n=100)$} \\
\hline & Total & $p$-value & Total & $p$-value \\
\hline Cough & $\begin{array}{l}97(75.8 \%) \\
\text { Productive cough }-\mathrm{n}=72\end{array}$ & $\begin{array}{l}0.000 \\
0.000\end{array}$ & $\begin{array}{c}17(17.0 \%) \\
\text { Productive cough }-n=10\end{array}$ & $\begin{array}{l}0.000 \\
0.000\end{array}$ \\
\hline Fever & $89(69.5 \%)$ & 0.372 & $64(64.0 \%)$ & 0.371 \\
\hline Weight loss & $85(53.1 \%)$ & 0.002 & $25(25.0 \%)$ & 0.000 \\
\hline Asthenia & $68(53.1 \%)$ & 0.002 & $35(35.0 \%)$ & 0.013 \\
\hline Anorexia & $65(50.8 \%)$ & 0.000 & $27(27.0 \%)$ & 0.000 \\
\hline Night sweats & $61(47.7 \%)$ & 0.001 & $27(27.0 \%)$ & 0.001 \\
\hline Chest pain & $32(25.0 \%)$ & 0.041 & $15(15.0 \%)$ & 0.077 \\
\hline Dyspnoea & $26(20.3 \%)$ & 0.004 & $6(6.0 \%)$ & 0.001 \\
\hline Haemoptysis & $10(7.8 \%)$ & 0.064 & $2(2.0 \%)$ & 0.042 \\
\hline Abdominal pain & $5(3.9 \%)$ & 0.149 & $11(11.0 \%)$ & 0.003 \\
\hline Nausea/vomiting & $5(3.9 \%)$ & 0.048 & $11(11.0 \%)$ & 0.023 \\
\hline Adenopathies & $4(3.1 \%)$ & 0.000 & $30(30.0 \%)$ & 0.000 \\
\hline Altered mental status & $3(2.3 \%)$ & 0.001 & $15(15.0 \%)$ & 0.000 \\
\hline Diarrhoea & $3(2.3 \%)$ & 0.288 & $6(6.0 \%)$ & 0.144 \\
\hline Back pain & $2(1.6 \%)$ & 0.000 & $17(17.0 \%)$ & 0.000 \\
\hline Headache & $2(1.6 \%)$ & 0.001 & $11(11.0 \%)$ & 0.003 \\
\hline Hemiparesis & $2(1.6 \%)$ & 0.653 & $4(4.0 \%)$ & 0.177 \\
\hline Hoarseness & $2(1.6 \%)$ & 0.510 & 0 & $N A$ \\
\hline Seizures & $1(0.8 \%)$ & 0.085 & $6(6.0 \%)$ & 0.008 \\
\hline Urinary symptoms & $1(0.8 \%)$ & 0.826 & $1(1.0 \%)$ & 0.887 \\
\hline
\end{tabular}

Note: p-value was calculated with Pearson $\chi 2$ test or Fisher's exact test. 
Table 5. Main methods used for diagnosis of TB in both groups

\begin{tabular}{|c|c|c|}
\hline & Pulmonary Tuberculosis $(n=128)$ & Extrapulmonary Tuberculosis $(n=100)$ \\
\hline \multirow[b]{2}{*}{$\begin{array}{l}\text { Acid-fast } \\
\text { smear }\end{array}$} & 106 positive tests $(82.8 \%)$ & 19 positive tests $(19.0 \%)$ \\
\hline & $\begin{array}{c}\text { Sputum }-n=92(86.8 \%) \\
\text { Gastric lavage }-n=14(13.2 \%) \\
\text { Bronchoalveolar fluid }-n=4(3.8 \%)\end{array}$ & $\begin{array}{c}\text { Gastric lavage }-n=5(26.3 \%) \\
\text { Biopsy }-n=4(21.1 \%) \\
\text { Sputum }-n=4(21.1 \%) \\
\text { Ganglion aspirate }-n=2(10.5 \%) \\
\text { Pleural effusion }-n=2(10.5 \%) \\
\text { Bronchoalveolar fluid }-n=1(5.3 \%) \\
\text { Cerebrospinal fluid }-n=1(5.3 \%)\end{array}$ \\
\hline \multirow[b]{2}{*}{ PCR } & 81 positive tests & 12 positive tests \\
\hline & $\begin{array}{c}\text { Sputum }-n=68(84.0 \%) \\
\text { Gastric lavage }-n=14(17.3 \%)\end{array}$ & $\begin{array}{c}\text { Sputum }-n=5(41.7 \%) \\
\text { Gastric lavage }-n=3(25.0 \%) \\
\text { Pleural effusion }-n=3(25.0 \%) \\
\text { Ganglion aspirate }-n=2(16.7 \%)\end{array}$ \\
\hline \multirow[b]{2}{*}{ Culture } & 102 positive tests & 13 positive tests \\
\hline & $\begin{array}{c}\text { Sputum }-\mathrm{n}=88(86.3 \%) \\
\text { Gastric lavage }-\mathrm{n}=18(14.1 \%) \\
\text { Bronchoalveolar fluid }-\mathrm{n}=2(2.0 \%)\end{array}$ & $\begin{array}{c}\text { Gastric lavage }-n=7(53.9 \%) \\
\text { Sputum }-n=4(30.8 \%) \\
\text { Biopsy }-n=1(7.7 \%) \\
\text { Bronchoalveolar fluid }-n=1(7.7 \%)\end{array}$ \\
\hline \multirow[b]{2}{*}{ Histology } & & 29 positive tests \\
\hline & & $\begin{array}{c}\text { Ganglion }-n=27(93.1 \%) \\
\text { Peritoneal }-n=4(13.8 \%) \\
\text { Gastrointestinal }-n=3(10.3 \%) \\
\text { Cerebral }-n=1(3.5 \%)\end{array}$ \\
\hline
\end{tabular}

Table 6. Initial therapeutic regimens

\begin{tabular}{|c|c|c|}
\hline & Pulmonary Tuberculosis $(n=128)$ & Extrapulmonary Tuberculosis $(\mathrm{n}=100)$ \\
\hline $\begin{array}{l}\text { Number } \\
\text { of drugs }\end{array}$ & $\begin{array}{c}4 \text { drugs }-n=120 \text { patients }(93.8 \%) \\
5 \text { drugs }-n=7 \text { patients }(5.5 \%) \\
6 \text { drugs }-n=1 \text { patient }(0.8 \%)\end{array}$ & $\begin{array}{c}4 \text { drugs }-n=92 \text { patients }(92.0 \%) \\
5 \text { drugs }-n=6 \text { patients }(6.0 \%) \\
6 \text { drugs }-n=2 \text { patient }(2.0 \%)\end{array}$ \\
\hline Drugs & 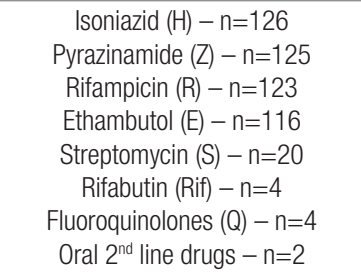 & $\begin{array}{c}\text { Isoniazid }-n=100 \\
\text { Pyrazinamide }-n=98 \\
\text { Ethambutol }-n=95 \\
\text { Rifampicin }-n=86 \\
\text { Rifabutin }-n=14 \\
\text { Streptomycin }-n=11 \\
\text { Fluoroquinolones }-n=6\end{array}$ \\
\hline $\begin{array}{l}\text { Main } \\
\text { therapeutic } \\
\text { regimens }\end{array}$ & $\begin{array}{c}\text { HRZE }-n=102 \\
\text { HRZS }-n=11 \\
\text { HRZES }-n=6 \\
\text { HRifZE }-n=4 \\
\text { (other regimens }-n=1 \text { : HRES, } \\
\text { HRESQ, HRZESQ, HRZS, RZEQ) }\end{array}$ & $\begin{array}{c}\text { HRZE }-n=74 \\
\text { HRifZE }-n=13 \\
\text { HRZES }-n=4 \\
\text { HRZS }-n=3 \\
\text { (other regimens }-n=1: \text { HRESQ, HRifESQ, } \\
\text { HRSQ, HRZQ) }\end{array}$ \\
\hline
\end{tabular}

[88,3-135,6] in pleural, 66,9 IU/L [56,9-71,1] in pericardic and 62,4 $\mathrm{IU} / \mathrm{L}[44,5-83,2]$ in gastrointestinal forms of TB. In PTB the median ADA level was 36,4 IU/L [28-58].

In patients with osteoarticular and meningeal tuberculosis, where the diagnosis was only deemed as possible, other diagnostic hypothesis like brucellosis, or different bacterial infections, were excluded. In osteoarticular forms biopsy was performed whenever possible. Most of biopsies yielded inconclusive results.

All patients were started on antituberculous therapy, mainly with the usual four drug scheme (isoniazid, rifampicin, pyrazinamide and ethambutol). Initial therapeutic regimens are described in table 6.

Some cases of drug-resistance were found ( $n=10-9$ in PTB group and 1 in the ETB group). None of the cases corresponded to multi-drug or extensive drug-resistance. Monoresistance was present in 3 cases (2 in PTB group - streptomycin, isoniazid; 1 in the ETB group - ethambutol) and polyresistance in 6 cases [all in the PTB group - streptomycin $(n=6)$, isoniazid $(n=4)$, ethambutol $(n=1)$, pyrazinamide $(n=1)]$. Four patients had resistance to isoniazid and streptomycin, one to streptomycin and pyrazinamide and another to streptomycin and ethambutol.

Adverse drug effects were observed in $32 \mathrm{pa-}$ tients (15, PTB and 17, ETB). In 84.4\% they manifested within the first two weeks of treatment and the remainder within a month. Major adverse effects were hepatotoxicity $(n=16$; $50.0 \%)$, rash $(n=9 ; 28.1 \%)$ and pancreatitis $(n=3 ; 9.4 \%)$. Angioedema, secondary lupus, nausea, nephrotoxicity, optic neuritis, vestibular toxicity and urticaria were also diagnosed $(n=1$; $3.1 \%)$.

Clinical outcome was favourable in most cases (PTB - $n=126,98.4 \%$ vs. ETB - $n=94,94.0 \%$ ). Eight patients died within the study period (PTB $n=2$ vs. $E T B n=6$ ).

A subanalysis of HIV-infected patients was performed. From 222 patients diagnosed with TB, 48 patients (21.6\%) had concurrent HIV infection (PTB $n=15$ vs. ETB $n=36, p$-value 0.052). Three patients had simultaneous pulmonary and extrapulmonary involvement. In both groups men were most commonly afflicted (PTB $n=12$, 80.0\%; ETB $n=29,80.6 \%$ ), with a median age of 39.5 years [PTB 34 years [31.5-43.0]; ETB 43 years [32.0-50.0]]. The length of stay was similar in both groups (PTB 17 days VS ETB 18 days). No statistical difference was found between PTB and ETB groups in HIV-infected patients.

CD4 count and viral load was obtained in 40 patients, revealing a median CD4 count of 74.5 cells/ $\mu \mathrm{L}$ [13-136] and a median viral load of 211,006 copies/mL $(1,430-4,430,000)$. In HIV patients, TB diagnosis mostly occurred in the context of newly diagnosed HIV infection $(n=34,70.8 \%)$. The remainder occurred in patients with poor adherence to HIV treatment regimens.

Disease location in HIV-infected patients was as follows: pulmonary $(n=15)$, disseminated $(n=11)$, lymphatic $(n=10)$, meningeal and pleural (both, $n=8)$ gastrointestinal $(n=3)$ and osteoarticular $(n=1)$. HIV infection was associated with presence of disseminated ( $p$-value 0.000 , $O R$ 12.64), pleural ( $p$-value $0.000, O R$ 8.50), meningeal ( $p$-value $0.000, O R 2.96)$ and lymphatic forms of TB (p-value 0.000, OR 2.38). HIV absence was associated with pulmonary (p-value 0.000, OR 4.08) and osteoarticular forms ( $p$-value 0.000, OR 5.42). 
TB cases in HIV patients were confirmed in 17 cases, deemed probable in 16 cases and considered as possible in 15 cases.

Six patients died in the HIV group (12.5\%) (PTB $n=1$, ETB $n=4$ and PTB+ETB $n=1)$. There was no particular prevalence of any TB form observed.

\section{Discussion}

Despite the decline in TB incidence in the past years in Portugal, the disease remains a major public health problem. $\cdot^{2-7}$ At our ward the number of cases also decreased between 2005-2014, both in pulmonary and extrapulmonary forms, reflecting the national tendency. PTB was the most frequent form of TB - as expected, taking into account national data available. ${ }^{3-7}$

HIV coinfection was also common in our ward reflecting national numbers. ${ }^{3}$ Tuberculosis is one of the most common opportunistic infections in this population and immunosuppression is a well-known risk factor for reactivation of TB 1,3,10,57. In a country where these two diseases are still an important issue, it is expected to find them simultaneously. Furthermore, at our hospital, HIV patients are mainly admitted to our, so one could expect this incidence.

An aspect worth highlighting was the higher frequency of TB in males, especially among those with PTB. Large prevalence studies also revealed that there is a sex bias. Men have more cases of PTB than women and that is true in all ages and most regions of the world. ${ }^{47}$ Biological factors can account for differences in resistance to infection between genders: it has been suggested a role of sex steroids and some genetic variants (like TLR8 polymorphisms) in host protection and susceptibility to TB, but more studies are needed. ${ }^{47,51}$ This gender bias is not restricted to TB, being reported in other bacterial infections in the literature. ${ }^{47}$ Nevertheless, there appears to be a tendency for more severe cases in women between 20-59 years of age, being TB one of the top five killers in this group worldwide. ${ }^{2}$

A relevant number of patients had ETB. This could be explained if we take into account the fact that some were co-infected with HIV or had other immunosuppressive conditions that could potentiate reactivation of latent forms of TB. The median age of patients with ETB was slightly higher than those with PTB. Despite the age difference expected when taking into account the later development of ETB in the general population, the age gap was lower than anticipated. This might be explained since in Portugal many people contact with TB throughout life, often at younger ages, which can lead to a relatively earlier reactivation of latent forms due to factors such as HIV infection and other immunosuppressive states.

Lymphatic TB was the most frequent form of ETB, followed by meningeal, osteoarticular and disseminated disease. Existing studies on the prevalence of ETB are quite contrasting and usually reflect local and regional differences, being difficult to reach any conclusions. ${ }^{13-18,65-68}$ Even so, in some studies, lymphatic TB stands out as the most common form of ETB. ${ }^{52-54}$ Some forms of TB were less frequent in our study than expected. That could be explained by the fact that some patients were probably hospitalized at other hospital wards before the diagnosis was reached (for example, pleural TB in Pneumology and pericardial TB in Cardiology).

The most frequent risk factors, for both groups, identified in this study are similar to the ones described in the literature. ${ }^{10,19-29,31,35}$

In patients with PTB, being a smoker was associated with an increased risk to acquire TB. In many studies active and passive smoking was found to be associated with TB infection/ disease, severity of disease, necessity of retreatment and mortality. These aspects seem to be independent of potential confounders like socioeconomic status and can be affected by the total dose of smoking. Some studies point to a possible influence of smoking in the higher incidence of TB observed in men. ${ }^{19,20}$

Like expected, contact with someone with active TB increases the risk to acquire PTB. This is a reminder of the importance of contact tracing and screening to identify all potentially related cases. Furthermore, if active disease is excluded, it remains paramount to consider latent TB and treat it, when appropriate, to reduce the risk of later reactivation. $8,36,37,55$

Persons that live in facilities or institutions like homeless shelters, correctional facilities and nursing homes, are at risk for PTB, as found in our study. Accordingly, they should be adequately monitored to achieve earlier diagnoses of TB. ${ }^{31,34,35,48}$

Immunosuppression is another risk factor to take in account. Infection by HIV, use of immunosuppressive therapy and presence of cancer, all are related with an increased development of TB. ${ }^{10,21-27}$ HIV greatly increases the risk of tuberculosis in both groups, which is confirmed in our data. In literature a direct relation to the degree of immunosuppression is described. HIV infection leads to more frequent extrapulmonary involvement, atypical manifestations and paucibacillary disease, which can delay diagnosis. The use of immunosuppressive therapy is increasing recently with the advent of monoclonal antibodies used to treat a growing number of diseases. Drugs like rituximab potentiate the reactivation of latent tuberculosis and the development of PTB. ${ }^{22,26}$ In the same way, chronic corticosteroid use can increase the risk of TB. ${ }^{23,24}$ In this study the number of patients under immunosuppressive therapy was small but sufficient to show an increased risk of PTB.

Lastly, people over 65 years old had an increased risk to develop ETB. This particular group is especially vulnerable to TB infection and reactivation of latent TB. Comorbidities, malnutrition and biological changes associated with ageing are some of the factors associated with this augmented risk. $^{28,29}$ Furthermore, institutionalized elderly people are more prone to have contact with TB. ${ }^{34,35}$ 
Other risk factors are described in scientific literature, but these revealed no statistically significant differences of increased risk in our study. This may be due to the limited number of patients analysed.

Most of the clinical manifestations identified in this study are similar to the ones found in the literature. Classical constitutional symptoms/signs like weight loss, asthenia and anorexia or the presence of cough and fever, are well established as very frequent in PTB patients. In ETB patients the symptoms are mostly mild, thus difficult to identify and easily confused with other diseases. Fever, a non-specific sign, seems to be the most common clinical feature. Despite that, the presence of focal symptoms can help guide the clinical investigation, like adenopathies in lymphatic forms and back pain in vertebral disease. ${ }^{8}$

Early diagnosis is important to achieve an effective treatment and reduce transmission of infection. ${ }^{48} \mathrm{~TB}$ can present with a variety of chest radiographic findings, including upper lung infiltrates, often with cavitations, middle or lower consolidations mimicking bacterial pneumonia, milliary patterns, nodule(s), pleural effusion and intrathoracic adenopathies. The chest radiography is a very useful tool for PTB diagnosis. Apical infiltrates and cavitations were the most frequent patterns found, in agreement with other studies. In ETB the chest radiography is less useful because many manifestations often occur at other locations. That aside, in some cases it can help in identifying patients with disseminated (micronodular pattern) and pleural forms (pleural effusion pattern). HIV patients presented mainly a normal chest radiography, apical infiltrates/consolidations or pleural effusion. Other imaging methods were used for diagnosis according to clinical suspicion, most of the times in ETB. $8,59,60$

Diagnosis of pulmonary TB is usually easier than in extrapulmonary forms of TB. A simple chest $\mathrm{x}$-ray, a thorough clinical history with a good physical examination, a simple sputum culture, nucleic acid amplification techniques or smear microscopy can help achieve the correct diagnosis. The multiple possible locations of disease, mild or inexistent symptoms and paucibacillary samples, can complicate the diagnosis of ETB. ${ }^{8,48}$ That is mirrored in the results obtained, where most of the times the ETB diagnosis was based only in clinical data and response to empiric treatment. Analytical data like ADA levels can help in supporting a diagnosis particularly in meningeal, pericardic, peritoneal and pleural forms of TB. ${ }^{61-66}$

Regarding treatment, the low rates of drug-resistance found should be noted, which is in accordance with national statistics. ${ }^{3,6,7}$ Furthermore, the absence of patients with MDR is important in highlighting the efficacy of the National Tuberculosis Program. Adverse effects of therapy were not common and in most cases occurred in the first weeks of treatment. Hepatotoxicity was the most frequent adverse effect, as expected. ${ }^{8,48,50}$
Although some patients had severity criteria or relevant comorbidities at diagnosis, the rate of mortality was low. This probably reflects the good health care assistance and also proper and timely initiation of treatment. The mortality seems to be higher in patients with ETB, which could be explained by the difficulty in establishing a diagnosis these patients, and with the presence of more extensive and severe disease in these cases than in PTB. HIV infection appears to have a central role in mortality, being present in almost all of the deceased. This seems to be in accordance with data found in the literature. $8,11,52-54,56$

One of the limitations of this study was the fact that the data was obtained retrospectively. It was extracted from medical records of patients that were hospitalized in the Infectious Diseases ward and that could be a selection bias. Reported odds ratios could be biased due to unmeasured or unknown confounders. Because of that, the data cannot be generalized to all patients with TB in Portugal - even so, it can point to some aspects that could be relevant in these patients. Pertaining this, however, our results are similar to other studies in the area. The small number of patients was another limitation. A larger sample could help reach other conclusions and find other relevant aspects about TB. Lack of data related to CD4 counts prevented a more careful assessment of the relevance of immunosuppression role in TB - six patients died and two were transferred to other institutions before collecting the necessary blood samples.

In conclusion, TB remains an important healthcare issue, although incidence is decreasing in Portugal. The diagnosis of TB can be difficult requiring a high degree of suspicion. Early diagnosis is essential to minimize morbidity and mortality from the disease. The conjugation of epidemiology, clinical aspects, imagiology and laboratory data allows early identification of these patients and appropriate and timely treatment. The presence of risk factors like HIV infection, contact with a TB-infected person, smoking or age over 65 are relevant and should be used to early identify people at risk of acquiring TB. HIV infection, in particular, leads to more frequent extrapulmonary involvement, atypical manifestations and paucibacillary disease, which can delay diagnosis.

Acknowledgements: This work was presented as a poster at the ECCMID (Amesterdam, April 2016).

Transparency Declaration: The authors declare no conflicts of interest.

\section{References}

1. Dheda K, Barry CE 3rd, Maartens G. Tuberculosis. Lancet 2015.

2. World Health Organization. Global Tuberculosis Report 2015. Available from: http://www. who.int/tb/publications/global_report/en/. [Accessed: 12/12/2015].

3. DGS. Programa Nacional para a Infeção VIH/SIDA. Portugal: Infeção por VIH, SIDA e Tuberculose em números - 2015. Direção-Geral de Saúde - Ministério da Saúde de Portugal. Novembro 2015, Lisboa.

4. European Centre for Disease Prevention and Control. Tuberculosis surveillance and monitoring in Europe. 2009-2015. Available from: http://ecdc.europa.eu/en/healthtopics/ Tuberculosis/epidemiological_data/Pages/tuberculosis_surveillance_Europe.aspx. [Accessed: 12/12/2015].

5. Pordata - Base de dados Portugal Contemporâneo. Tuberculose. 2015. Available from: http://www.pordata.pt/Pesquisa/tuberculose. [Accessed: 12/12/2015].

6. Administração Regional de Saúde do Centro, I.P. Relatório de Atividades. 2014. Available from: http://www.arscentro.min-saude.pt/Institucional/Documents/monitor- 
iza\%C3\%A7\%C3\%A30\%20e\%20avalia\%C3\%A7\%C3\%A30/Relat\%C3\%B3rio\%20 de\%20Atividades\%202014 \%20ARS\%20Centro\%20(enviado\%20para\%20DGS) pdf. [Accessed: 12/12/2015].

7. Administração Regional de Saúde do Centro, I.P. Plano de Atividades. 2014. Available from: http://www.arscentro.min-saude.pt/Institucional/Documents/monitorização\%20 e\%20avaliação/Plano\%20de\%20Atividades\%202014\%20ARS\%20Centro_VAprovada.pdf. [Accessed: 12/12/2015]

8. Centers for Disease Control and Prevention. Tuberculosis: Basic TB Facts. http://www. cdc.gov/tb/topic/basics/risk.htm (Accessed on March 10, 2015).

9. Sloot R, Schim van der Loeff MF, Kouw PM, Borgdorff MW. Risk of tuberculosis after recent exposure. A 10-year follow-up study of contacts in Amsterdam. Am J Respir Crit Care Med 2014; 190:1044

10. Hwang J et al. Incidence and Risk factors of Tuberculosis in Patients with Human Immunodeficiency Virus Infection. J Korean Med Sci 2013: 28: 374-377.

11. Ramirez-Lapausa M, Menendez Saldana A and Noguerado-Asensio A. Extrapulmonary tuberculosis: an overview. Rev Esp Sanid Penit 2015; 17:3-11.

12. Lee J. Diagnosis and Treatment of Extrapulmonary tuberculosis. Tuberc RespirDis 2015; 78:47-55

13. Kulchavenya E. Extrapulmonary tuberculosis: are statistical reports accurate?. Ther Adv Infect Dis 2014; 2 (2): 61-70.

14. Chandir S et al. Extrapulmonary Tuberculosis: A retrospective review of 194 cases at a tertiary care hospital in Karachi, Pakistan. J Pak Med Assoc 2010; 60 (2): 105-09.

15. Fader T, Parks J, Khan N, Manning R, Stokes S and Nasir N. Extrapulmonary tubercuIosis in Kabul, Afghanistan: A hospital-based retrospective review. International Journa of Infectious Diseases 2010; 10: e102-e110.

16. Wang X, Yang Z, Fu Y, Zhang G, Wang X, Zhang Y and Wang X. Insight of Epidemiology and Risk Factors of Extrapulmonary Tuberculosis in Tianjin, China during 2006-2011. Plos One,2014. 1-12

17. Gunal S, Yang Z, Agarwal M, Koroglu M, Anci Z and Durmaz R. Demographic and microbial characteristics of extrapulmonary tuberculosis cases diagnosed in Malatya, Turkey, 2001-2007. BMC Public Health 2011; 11: 154

18. Guzmán et al. Clinical and epidemiological features of extrapulmonary tuberculosis in a high incidence region. Salud pública de México. 2014. Vol 56, n² 2: 189-196.

19. Leung CC, Yew WW, Chan CK, et al. Smoking adversely affects treatment response outcome and relapse in tuberculosis. Eur Respir J 2015; 45:738.

20. Slama K, Chiang CY, Enarson DA, et al. Tobacco and tuberculosis: a qualitative systematic review and meta-analysis. Int J Tuberc Lung Dis. 2007 Oct. 11(10):1049-61.

21. Bendayan D, Littman K and Polansky V. Active tuberculosis and Human Immunodeficiency Virus Co-Infection In Israel: A Retrospective Study. IMAJ 2010; 12: 100-103.

22. Chung KB, Lee EY, Im JP, Han SK and Yim J. Clinical characteristics and treatment responses of patients who developed tuberculosis following use of a tumor necrosis factor- $\alpha$ inhibitor. Korean J Intern Med 2014; 28:174-179.

23. Dong YH, Chang $\mathrm{CH}$, Lin Wu FL, et al. Use of inhaled corticosteroids in patients with COPD and the risk of TB and influenza: A systematic review and meta-analysis of randomized controlled trials. a systematic review and meta-analysis of randomized controlled trials. Chest 2014; 145:1286

24. Jick SS, Lieberman ES, Rahman MU, Choi HK. Glucocorticoid use, other associated factors, and the risk of tuberculosis. Arthritis Rheum 2006; 55:19.

25. Kamboj M, Sepkowitz KA. The risk of tuberculosis in patients with cancer. Clin Infect Dis 2006; 42:1592.

26. Keane J, Gershon S, Wise RP, et al. Tuberculosis associated with infliximab, a tumor necrosis factor alpha-neutralizing agent. N Engl J Med. 2001 Oct 11. 345(15):1098-104.

27. Leeds IL et al. Site of Extrapulmonary Tuberculosis is Associated with HIV Infection Clinical Infectious Diseases 2012; 55(1): 75-81.

28. Donald PR, Marais BJ and Barry CE 3rd. Age and the epidemiology and pathogenesis of tuberculosis. Lancet 2010; 375: 1852-1854.

29. Lin C et al. Effects of Gender and Age on Development of Concurrent Extrapulmonary Tuberculosis in Patients with Pulmonary Tuberculosis: A Population Based Study. PloS One 2013; Vol 8, Issue 5: 263936

30. Campbell JR et al. Latent tuberculosis infection screening in immigrants to low-incidence countries: a meta-analysis. Mol Diagn Ther 2015; 19(2): 107-117.

31. Jiménez-Fuentes MA et al. Screening for active tuberculosis in high-risk groups. Int J Tuberc Lung Dis. 2014; 18(12):1459-65.

32. Räisänen PE et al. Tuberculosis in immigrants in Finland 1995-2013. Epidemiol Infect 2016; 144(2): 425-433

33. Aquillera XP et al. Tuberculosis in prisoners and their contacts in Chile: estimating incidence and latent infection. Int J Tuberc Lung Dis 2016; 20(1):63-70.

34. Korzeniewska-Kosela M, Kus J, Lewandowska K and Siemion-Szczesniak I. Tuberculosis in homeless persons in Poland. Przegl Epidemiol. 2015; 69(3):445-51, 575-80.

35. Munn MS, Duchin JS, Kay M, Pecha M, Thibault CS and Narita M. Analysis of risk factors for tuberculous infection following exposure at a homeless shelter. Int J Tuberc Lung Dis. 2015; 19(5):570-5.

36. Jensen PA, Lambert LA, lademarco MF, et al. Guidelines for preventing the transmission of Mycobacterium tuberculosis in health-care settings, 2005. MMWR Recomm Rep $2005 ; 54: 1$.
37. Verhagen LM, van den Hof S, van Deutekom $H$, et al. Mycobacterial factors relevant for transmission of tuberculosis. J Infect Dis. 2011 May. 203(9):1249-55.

38. World Health Association. Policy Guidelines for Collaborative TB and HIV Services for Injecting and Other Drug Users: An Integrated Approach. 2008. Available from: http:// apps.who.int/iris/bitstream/10665/43937/1/9789241596930_eng.pdf. (Accessed 12/12/2015)

39. Lönnroth K, Williams BG, Stadlin S, et al. Alcohol use as a risk factor for tuberculosis - a systematic review. BMC Public Health 2008; 8:289.

40. Cegielski JP, McMurray DN. The relationship between malnutrition and tuberculosis: evidence from studies in humans and experimental animals. Int J Tuberc Lung Dis 2004; 8:286.

41. Baker MA, Lin HH, Chang HY, Murray MB. The risk of tuberculosis disease among persons with diabetes mellitus: a prospective cohort study. Clin Infect Dis 2012; 54:818.

42. Hongguang C, Min L, Shiwen J, et al. Impact of diabetes on clinical presentation and treatment outcome of pulmonary tuberculosis in Beijing. Epidemiol Infect 2015; 143:150.

43. Hussein MM, Mooij JM, Roujouleh H. Tuberculosis and chronic renal disease. Semin Dial 2003; 16:38.

44. Lin YT, Wu PH, Lin CY, et al. Cirrhosis as a risk factor for tuberculosis infection--a nationwide longitudinal study in Taiwan. Am J Epidemiol 2014; 180: 103

45. Thulstrup AM, Mølle I, Svendsen N, Sørensen HT. Incidence and prognosis of tuberculosis in patients with cirrhosis of the liver. A Danish nationwide population based study. Epidemiol Infect 2000; 124:221.

46. Leung CC, Lam TH, Chan WM, et al. Lower risk of tuberculosis in obesity. Arch Intern Med. 2007 Jun 25. 167(12):1297-304.

47. Neyrolles 0 and Quintana-Murci L. Sexual Inequality in Tuberculosis. PloS Medicine 2009; Vol 6, Issue 12: 1-6.

48. TB CARE I and UNAIDS. International Standards for Tuberculosis Care. 2014. 3th Edition. Available from: http://www.who.int/tb/publications/ISTC_3rdEd.pdf. (Accessed 12/12/2015)

49. Horsburgh CR Jr, Barry CE 3rd, Lange C. Treatment of Tuberculosis. N Engl J Med 2015; $373: 2149$

50. World Health Organization. Treatment of tuberculosis guidelines (4th edition). whqlibdoc.who.int/publications/2010/9789241547833_eng.pdf (Accessed 12/12/2015).

51. Marriott I and Huet-Hudson YM. Sexual dimorphism in innate immune responses to infectious organisms. Immunol Res 2006; 34: 177-192.

52. Guler $\mathrm{S}$ et al. Evaluation of Pulmonary and Extrapulmonary Tuberculosis in Immunocompetent Adults: A restrospective Case Series Analysis. Med Princ Pract 2015; 24: 75-79.

53. Sreeramareddy CT, Panduru KV, Verma SC, Joshi HS, Bates MN. Comparison of pulmonary and extrapulmonary tuberculosis in Nepal- a hospital-based retrospective study. BMC Infect Dis. 2008;8:8.

54. Sunnetcioglu $A$ et al. Comparative analysis of pulmonary and extrapulmonary tuberculosis of 411 cases. Annals of Clinical Microbiology and Antimicrobials 2015; 14:34.

55. Getahun H, Matteelli A, Chaisson RE, Raviglione M. Latent Mycobacterium tuberculosis infection. N Engl J Med 2015; 372:2127

56. Havlir DV, Getahun H, Sanne I, Nunn P. Opportunities and challenges for HIV care in overlapping HIV and TB epidemics. JAMA 2008; 300:423.

57. Panel on Opportunistic Infections in HIV-Infected Adults and Adolescents. Guidelines for the prevention and treatment of opportunistic infections in HIV-infected adults and adolescents: Recommendations from the Centers for Disease Control and Prevention, the National Institutes of Health, and the HIV Medicine Association of the Infectious Diseases Society of America. Available at: http://aidsinfo.nih.gov/contentfiles/lvguidelines/ adult_oi.pdf (Accessed 12/12/2015).

58. Sterling $T$ et al. Risk Factors for Tuberculosis after Highly Active Antiretroviral Therapy Initiation in the United States and Canada: Implications for Tuberculosis Screening. The Journal of Infectious Diseases 2011;204: 893-901.

59. Daley CL, Gotway MB, Jasmer RM. Radiographic Manifestations of Tuberculosis: A Primer for Clinicians, 2nd Edition, Francis, J (Ed). Curry National TB Center, 2006. Available at: http://www.nationaltbcenter.edu/radiographic/ (Accessed at 12/12/2015)

60. Skoura E, Zumla A and Bomanij J. Imaging in Tuberculosis. Internation Journal of Infectious Diseases 2015; 31: 87-93

61. Gui $X$ and Xiao H. Diagnosis of tuberculosis pleurisy with adenosine deaminase (ADA): a systematic review and meta-analysis. Int J Clin Exp Med 2014; 7(10): 3126-35

62. Boonyagars L. Use of Adenosine Deaminase for the diagnosis of Tuberculosis: A Review. $\mathrm{J}$ Infect Dis Antimicrob Agents 2010; 27 (2): 111-118.

63. Tuon FF et al. Adenosine deaminase and tuberculous meningitis - a systematic review with meta-analysis. Scand J Infect Dis 2010; 42 (3): 198-207.

64. Afrasiabian $\mathrm{S}$ et al. Diagnostic value of serum adenosine deaminase level in pulmonary tuberculosis. J res Med Sci 2013; 18(3): 252-254.

65. Tao $\mathrm{L}$ et al. Diagnostic value of adenosine deaminase in ascites for tuberculosis ascites: a meta-analysis. Diagn Microbiol Infect Dis 2014; 79(1): 102-107.

66. Lee JY. Diagnosis and Treatment of Extrapulmonary Tuberculosis. Tuberc Respir Dis. 2015 Apr; 78 (2): 47-55 